\title{
Electrochemical Reduction of Carbon Dioxide on Nitrogen-Doped Carbons: Insights from Isotopic Labeling Studies
}

\author{
Dorottya Hursán ${ }^{\dagger,+}$ and Csaba Janáky ${ }^{*}, \dagger, \ddagger$ \\ ${ }^{\dagger}$ Department of Physical Chemistry and Materials Science, University of Szeged, Rerrich Square 1, Szeged H-6720, Hungary \\ ${ }^{\ddagger}$ MTA-SZTE “Lendület” Photoelectrochemistry Research Group, Rerrich Square 1, Szeged H-6720, Hungary
}

Supporting Information

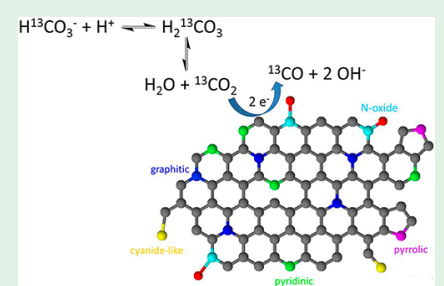

ABSTRACT: Isotopic labeling experiments were performed to better understand the electrochemical reduction of carbon dioxide on nitrogen-doped porous carbon electrodes. By using nonequilibrated solutions of selectively labeled initial carbon sources (i.e., ${ }^{13} \mathrm{CO}_{2}$ and $\left.\mathrm{H}^{13} \mathrm{CO}_{3}{ }^{-}\right)$, bicarbonate anion was identified as the predominant source of the carbon monoxide reduction product.

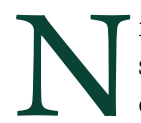
itrogen-doped carbon materials are increasingly studied in energy-oriented electrochemical and photoelectrochemical reactions as active materials and conductive scaffolds. ${ }^{1}$ After demonstrating their catalytic activity in the electrochemical oxygen reduction reaction, ${ }^{2,3}$ there is growing interest toward $\mathrm{H}_{2}$ evolution ${ }^{4}$ and $\mathrm{CO}_{2}$ conversion, too. $^{5-9}$ Impressive activities were reported in $\mathrm{CO}_{2}$ reduction, which makes these cheap materials potential rivals to their more expensive inorganic counterparts. Both experimental and theoretical studies investigated mechanistic aspects to identify the active center. The chemical nature of the $\mathrm{C}-\mathrm{N}$ moiety seems to be a decisive factor, where pyridinic $\mathrm{N}$ and a $\mathrm{C}$ atom next to pyridinic $\mathrm{N}$ were the most active. ${ }^{6}$ Despite the steeply growing number of papers on $\mathrm{CO}_{2}$ electroreduction using carbon-based electrodes, there are only a very few papers where any kind of isotopic labeling was performed to confirm the source of $\mathrm{CO}_{2}$ reduction products. ${ }^{5,9,10}$ On the other hand, detailed studies were carried out on gold ${ }^{11}$ and copper ${ }^{12}$ electrodes, where the electroreduction process was monitored by surface-sensitive infrared spectroscopy and mass spectrometry. In other instances, NMR spectroscopy was employed to identify ${ }^{13} \mathrm{C}$ in the liquid phase reduction products on gold and copper electrodes. ${ }^{13,14}$ At the same time, the question still holds, what is the source of the assumed $\mathrm{CO}_{2}$ reduction products in such cases? The dissolved
$\mathrm{CO}_{2}$, the bicarbonate ions, $\mathrm{CO}_{2}$ furnished through the carbon dioxide-bicarbonate equilibrium, or the electrode material itself? To answer this question, we performed the first systematic isotopic labeling study employing a N-doped carbon electrode. The fact that it takes around $2 \mathrm{~h}$ to reach the equilibrium conditions between the bicarbonate ions and $\mathrm{CO}_{2}$ (Figure S2) allowed selective or joint labeling of the carbon sources $\left(\mathrm{CO}_{2}\right.$ and $\mathrm{HCO}_{3}{ }^{-}$), and electrogenerated $\mathrm{CO}$ was analyzed by $\mathrm{GC}-\mathrm{MS}$.

A highly porous, high surface area $\mathrm{N}$-doped carbon catalyst (HPG-PPy) was synthesized by adaptation of a literature procedure $^{15}$ (see details in the SI). Product analysis during potentiostatic electrolysis revealed the formation of $\mathrm{CO}$ and $\mathrm{H}_{2}$ as main products (Figure S1D). The amounts of $\mathrm{CO}$ and $\mathrm{H}_{2}$ were similar at moderate overpotentials $(-0.61$ and $-0.71 \mathrm{~V})$ and scaled linearly with the reduction charge (Figure 1A). First, joint isotopic labeling experiments (i.e., both the $\mathrm{CO}_{2}$ gas- and bicarbonate-labeled) were carried out, and the exclusive formation of ${ }^{13} \mathrm{CO}$ confirmed that indeed the $\mathrm{CO}_{2} /$ bicarbonate feedstock was converted (Figure S3). To have a deeper understanding of the $\mathrm{CO}_{2}$ reduction mechanism on the carbon catalyst, especially to find out whether the bicarbonate or the aqueous $\mathrm{CO}_{2}$ is the reacting species, the two carbon sources were selectively labeled. When the bicarbonate was the labeled component and we were operating under nonequilibrium conditions (see SI section 1.3 for details), in the first hour of electrolysis, the majority of the $\mathrm{CO}$ was ${ }^{13} \mathrm{C}$-labeled. Within this time frame, the isotopic equilibrium was not yet established between bicarbonate ions and $\mathrm{CO}_{2}$ gas (Figure S2). The ${ }^{13} \mathrm{CO} /{ }^{12} \mathrm{CO}$ ratio gradually decreased and approached the ratio characteristic of the equilibrium conditions during the $2 \mathrm{~h}$ electrolysis (Figure 1B). On the other hand, when the $\mathrm{CO}_{2}$ gas was labeled, the opposite trend was observed (Figure 1C). As in the case of nonequilibrated precursor solution, the isotopic composition of the $\mathrm{CO}$ product mirrored that of bicarbonate ions; it seems that $\mathrm{CO}$ either originates directly from the reduction of bicarbonate or from the aqueous $\mathrm{CO}_{2}$ supplied through the fast equilibrium with the bicarbonate ions (but not from the dissolved $\mathrm{CO}_{2}$ in the bulk solution). This latter mechanism was suggested for $\mathrm{Au}$ and $\mathrm{Cu}$ electrodes. ${ }^{11,12}$

Received: February 7, 2018

Accepted: February 19, 2018

Published: February 19, 2018 

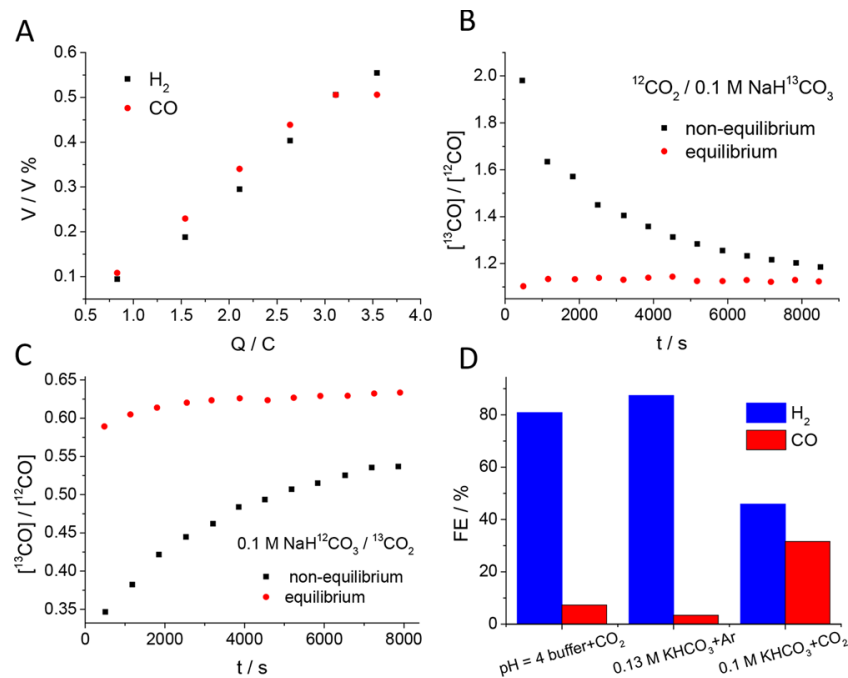

Figure 1. (A) Concentration of $\mathrm{CO}$ and $\mathrm{H}_{2}$ generated on the HPGPPy electrode with increasing reduction charge during potentiostatic electrolysis at $-0.71 \mathrm{~V}$ (vs RHE) in a $\mathrm{CO}_{2}$-saturated $0.1 \mathrm{M}$ $\mathrm{KHCO}_{3}$ electrolyte. (B) Ratio of the concentration of ${ }^{13} \mathrm{CO}$ to ${ }^{12} \mathrm{CO}$ formed during potentiostatic electrolysis at $-0.71 \mathrm{~V}$ (vs RHE) in a ${ }^{12} \mathrm{CO}_{2}$-saturated $0.1 \mathrm{M} \mathrm{NaH}{ }^{13} \mathrm{CO}_{3}$ electrolyte under nonequilibrium and equilibrium conditions. (C) Ratio of the concentration of ${ }^{13} \mathrm{CO}$ to ${ }^{12} \mathrm{CO}$ formed during potentiostatic electrolysis at $-0.71 \mathrm{~V}$ (vs $\mathrm{RHE}$ ) in a ${ }^{13} \mathrm{CO}_{2}$-saturated $0.1 \mathrm{M}$ $\mathrm{NaH}^{12} \mathrm{CO}_{3}$ electrolyte under nonequilibrium and equilibrium conditions. (D) Faradaic efficiencies of $\mathrm{H}_{2}$ and $\mathrm{CO}$ formation at the 75th minute of electrolysis at $-0.61 \mathrm{~V}$ (vs RHE) in different electrolytes: (i) $\mathrm{CO}_{2}$-saturated $0.1 \mathrm{M}$ phosphate buffer $(\mathrm{pH}=3.8)$; (ii) Ar-saturated $0.13 \mathrm{M} \mathrm{KHCO}_{3}(\mathrm{pH}=8.8)$; (iii) $\mathrm{CO}_{2}$-saturated $0.1 \mathrm{M} \mathrm{KHCO}_{3}(\mathrm{pH}=6.6)$.

To decide whether the $\mathrm{CO}_{2}$ or the $\mathrm{HCO}_{3}{ }^{-}$is the actual reacting species, a set of control experiments was performed. The concentration of bicarbonate ions and $\mathrm{CO}_{2, \mathrm{aq}}$ and the $\mathrm{pH}$ cannot be controlled independently because of the existing equilibrium. We can operate at $\mathrm{pH}$ values, however, where dominantly only one species is present. If the $\mathrm{pH}$ is below 5, almost all of the dissolved $\mathrm{CO}_{2}$ is in the form of $\mathrm{CO}_{2}$ aq, while between $\mathrm{pH} 7$ and 9, mainly bicarbonate is present in the solution. ${ }^{16}$ Thus, we performed electrolysis in (i) $\mathrm{CO}_{2}$ saturated $0.1 \mathrm{M}$ phosphate buffer $(\mathrm{pH}=3.8)$, (ii) $0.13 \mathrm{M}$ $\mathrm{KHCO}_{3}$ solution saturated with $\mathrm{Ar}(\mathrm{pH}=8.8)$, and (iii) $\mathrm{CO}_{2}$ saturated $0.1 \mathrm{M} \mathrm{KHCO}_{3}(\mathrm{pH}=6.6)$, at $-0.61 \mathrm{~V}$ vs RHE in all cases (Figure 1D). The Faradaic efficiency of $\mathrm{CO}$ formation $\left(\mathrm{FE}_{\mathrm{CO}}\right)$ was $31.6 \%$ in the $\mathrm{CO}_{2}$-saturated $0.1 \mathrm{M} \mathrm{KHCO}_{3}$, while it was only $3.4 \%$ in the Ar-saturated $0.13 \mathrm{M} \mathrm{KHCO}_{3}$. Although the total dissolved $\mathrm{CO}_{2}$ content of the two electrolytes is approximately the same, the $\mathrm{CO}_{2}$ aq concentration is around 40 times higher for the $\mathrm{CO}_{2}$-saturated $0.1 \mathrm{M} \mathrm{KHCO}_{3}$ (see SI section 5). In the $\mathrm{CO}_{2}$-saturated $\mathrm{pH}=3.8$ buffer, the $\mathrm{FE}_{\mathrm{CO}}$ was $7.3 \%$, higher than that in the case of the Ar-saturated electrolyte, probably because of the much higher $\mathrm{CO}_{2, \text { aq }}$ concentration. The fact that $\mathrm{FE}_{\mathrm{CO}}$ in the $\mathrm{CO}_{2}$-saturated $\mathrm{pH}=$ 3.8 buffer is much lower than in the $\mathrm{CO}_{2}$-saturated $0.1 \mathrm{M}$ $\mathrm{KHCO}_{3}$ solution suggests the vital role of bicarbonate ions acting as a $\mathrm{CO}_{2}$ source. Notably, a very similar trend was seen in the partial current densities to what was presented for the FE values.

Overall, findings from selective isotopic labeling and $\mathrm{pH}$ dependent studies demonstrated that the reacting species at the surface of a $\mathrm{N}-\mathrm{C}$ electrode is most likely $\mathrm{CO}_{2, \mathrm{aq}}$. Dissolved
$\mathrm{CO}_{2}$ at the electrode surface, however, is rapidly supplied by bicarbonate ions (acting as a " $\mathrm{CO}_{2}$ buffer"), if present, rather than gas-phase $\mathrm{CO}_{2}$ or that dissolved in bulk solution. This assumption explains why the isotopic composition of the $\mathrm{CO}$ product is similar to that of bicarbonate when the isotopic equilibrium is not yet established. The fact that the highest $\mathrm{FE}_{\mathrm{CO}}$ was obtained for the bicarbonate $/ \mathrm{CO}_{2}$ system and that it was significantly lower when $\mathrm{CO}_{2, \mathrm{aq}}$ was present without bicarbonate further supports this hypothesis. Direct bicarbonate reduction is unlikely as only very small amounts of $\mathrm{CO}$ were produced when practically only bicarbonate ions were present. This mechanism was also suggested for a $\mathrm{Ni}-\mathrm{N}-\mathrm{C}$ catalyst based on the dependence of the $\mathrm{CO}$ partial current density on bicarbonate concentration. ${ }^{17}$ Further efforts are ongoing to elucidate the mechanism of the electrochemical $\mathrm{CO}_{2}$ reduction on $\mathrm{N}$-doped carbon electrodes because these insights are very important in designing new electrode and electrochemical cell configurations to scale up this promising technology. ${ }^{18,19}$

\section{ASSOCIATED CONTENT}

\section{Supporting Information}

The Supporting Information is available free of charge on the ACS Publications website at DOI: 10.1021/acsenergylett.8b00212.

Electrode preparation, electrochemical measurements, and related mass spectrometry data (PDF)

\section{AUTHOR INFORMATION}

\section{Corresponding Author}

*E-mail: janaky@chem.u-szeged.hu. Twitter: @JanakyLab.

ORCID

Csaba Janáky: 0000-0001-5965-5173

Notes

The authors declare no competing financial interest.

\section{ACKNOWLEDGMENTS}

This project received funding from the European Research Council (ERC) under the European Union's Horizon 2020 programme (Grant 716539). This work was supported by the GINOP-2.2.1-15-2017-00041 project.

\section{REFERENCES}

(1) Yang, N.; et al. ACS Appl. Mater. Interfaces 2016, 8, 2835728371.

(2) Pan, F.; et al. J. Mater. Chem. A 2017, 5, 13104-13111.

(3) Zhu, C.; et al. Chem. Soc. Rev. 2016, 45, 517-531.

(4) Lai, J.; et al. Energy Environ. Sci. 2016, 9, 1210-1214.

(5) Wu, J.; et al. Nat. Commun. 2016, 7, 13869.

(6) Duan, X.; et al. Adv. Mater. 2017, 29, 1701784.

(7) Liu, T.; et al. J. Mater. Chem. A 2017, 5, 21596-21603.

(8) Ju, W.; et al. Nat. Commun. 2017, 8, 944.

(9) Song, Y.; et al. Angew. Chem., Int. Ed. 2017, 56, 10840-10844.

(10) Jiang, K.; et al. Chem. 2017, 3, 950-960.

(11) Dunwell, M.; et al. J. Am. Chem. Soc. 2017, 139, 3774-3783.

(12) Zhu, S.; et al. J. Am. Chem. Soc. 2017, 139, 15664-15667.

(13) Han, Z.; et al. ACS Cent. Sci. 2017, 3, 853-859.

(14) Cave, E. R.; et al. Phys. Chem. Chem. Phys. 2017, 19, 1585615863.

(15) To, J. W. F.; et al. ACS Cent. Sci. 2015, 1, 68-76.

(16) Zhong, H.; et al. J. Phys. Chem. C 2015, 119, 55-61.

(17) Zhao, C.; et al. J. Am. Chem. Soc. 2017, 139, 8078-8081.

(18) Endrődi, B.; et al. Prog. Energy Combust. Sci. 2017, 62, 133-154.

(19) Janáky, C.; et al. ACS Energy Lett. 2016, 1, 332-338. 